\title{
Arterial Blood Gases and Oxygen Content in Climbers on Mount Everest
}

\author{
Michael P.W. Grocott, M.B., B.S., Daniel S. Martin, M.B., Ch.B., \\ Denny Z.H. Levett, B.M., B.Ch., Roger McMorrow, M.B., B.Ch., \\ Jeremy Windsor, M.B., Ch.B., and Hugh E. Montgomery, M.B., B.S., M.D., \\ for the Caudwell Xtreme Everest Research Group*
}

From the Centre for Altitude, Space, and Extreme Environment Medicine, University College London Institute of Human Health and Performance, London. Address reprint requests to $\mathrm{Dr}$. Grocott at the Centre for Altitude, Space, and Extreme Environment Medicine, University College London Institute of Human Health and Performance, 1st Fl., Charterhouse Bldg., Archway Campus, Highgate Hill, London N19 5LW, United Kingdom, or at mike. grocott@ucl.ac.uk.

Drs. Grocott and Martin contributed equally to this article.

*The members of the Caudwell Xtreme Everest Research Group are listed in the Appendix.

N Engl J Med 2009;360:140-9.

Copyright (c) 2009 Massachusetts Medical Society.

\section{A BSTRACT}

\section{BACKGROUND}

The level of environmental hypobaric hypoxia that affects climbers at the summit

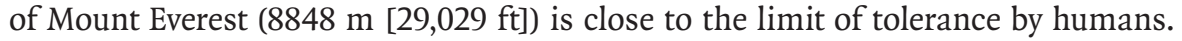
We performed direct field measurements of arterial blood gases in climbers breathing ambient air on Mount Everest.

\section{METHODS}

We obtained samples of arterial blood from 10 climbers during their ascent to and descent from the summit of Mount Everest. The partial pressures of arterial oxygen $\left(\mathrm{PaO}_{2}\right)$ and carbon dioxide $\left(\mathrm{PaCO}_{2}\right), \mathrm{pH}$, and hemoglobin and lactate concentrations were measured. The arterial oxygen saturation $\left(\mathrm{SaO}_{2}\right)$, bicarbonate concentration, base excess, and alveolar-arterial oxygen difference were calculated.

\section{RESULTS}

$\mathrm{PaO}_{2}$ fell with increasing altitude, whereas $\mathrm{SaO}_{2}$ was relatively stable. The hemoglobin concentration increased such that the oxygen content of arterial blood was maintained at or above sea-level values until the climbers reached an elevation of $7100 \mathrm{~m}$ $(23,294 \mathrm{ft})$. In four samples taken at $8400 \mathrm{~m}(27,559 \mathrm{ft})$ - at which altitude the barometric pressure was $272 \mathrm{~mm} \mathrm{Hg}(36.3 \mathrm{kPa})$ - the mean $\mathrm{PaO}_{2}$ in subjects breathing ambient air was $24.6 \mathrm{~mm} \mathrm{Hg}(3.28 \mathrm{kPa})$, with a range of 19.1 to $29.5 \mathrm{~mm} \mathrm{Hg}$ (2.55 to $3.93 \mathrm{kPa}$ ). The mean $\mathrm{PaCO}_{2}$ was $13.3 \mathrm{~mm} \mathrm{Hg}(1.77 \mathrm{kPa})$, with a range of 10.3 to $15.7 \mathrm{~mm} \mathrm{Hg}$ (1.37 to $2.09 \mathrm{kPa}$ ). At $8400 \mathrm{~m}$, the mean arterial oxygen content was $26 \%$ lower than it was at $7100 \mathrm{~m}$ (145.8 ml per liter as compared with $197.1 \mathrm{ml}$ per liter). The mean calculated alveolar-arterial oxygen difference was $5.4 \mathrm{~mm} \mathrm{Hg}$ $(0.72 \mathrm{kPa})$.

\section{CONCLUSIONS}

The elevated alveolar-arterial oxygen difference that is seen in subjects who are in conditions of extreme hypoxia may represent a degree of subclinical high-altitude pulmonary edema or a functional limitation in pulmonary diffusion. 
T HE PARTIAL PRESSURE OF ATMOSPHERIC oxygen falls progressively as barometric pressure decreases with increasing altitude. Correspondingly, the ability to perform work (e.g., walking or climbing) diminishes with the decreased availability of atmospheric oxygen for aerobic respiration. ${ }^{1,2}$ At the summit of Mount Everest (8848 m [29,029 ft]), the highest point on the earth's surface, the partial pressure of inspired oxygen $\left(\mathrm{PIO}_{2}\right)$ is believed to be very close to the limit that acclimatized humans can tolerate while maintaining functions such as ambulation and cognition. ${ }^{3}$ Hillary and Tenzing used supplemental oxygen to achieve the first ascent of Everest in 1953. It was not until 25 years after their ascent that the first ascent of Everest without supplemental oxygen was made by Messner and Habeler. ${ }^{4}$ Currently, less than $4 \%$ of persons who climb Everest do so without the use of supplemental oxygen (Salisbury R., Himalayan database: personal communication).

The only published measurements of the partial pressure of oxygen in arterial blood $\left(\mathrm{PaO}_{2}\right)$ at such a low barometric pressure were reported in two studies - Operation Everest II and Operation Everest III (Comex '97) — that were designed to simulate an ascent of Mount Everest by placing subjects in a hypobaric chamber. ${ }^{5,6}$ The subjects in the two studies had a mean $( \pm S D)$ resting $\mathrm{PaO}_{2}$ of $30.3 \pm 2.1 \mathrm{~mm} \mathrm{Hg}(4.04 \pm 0.28 \mathrm{kPa})^{5}$ and $30.6 \pm 1.4 \mathrm{~mm} \mathrm{Hg}(4.08 \pm 0.19 \mathrm{kPa}),{ }^{6}$ respectively, at a barometric pressure equivalent to the summit of Mount Everest (253.0 mm Hg, or $33.73 \mathrm{kPa}$ ). Such profound hypoxemia was tolerable because the subjects had been gradually acclimatized to the simulated altitude over a period of 37 to 40 days. In 1981, the partial pressures of oxygen and carbon dioxide $\left(\mathrm{PaCO}_{2}\right)$ at end expiration were measured in a single person on Everest's summit after the person had been breathing without supplemental oxygen for approximately $10 \mathrm{~min}$ utes. ${ }^{7}$ With the use of a classic Bohr integration, the $\mathrm{PaO}_{2}$ for this climber was estimated to be $28 \mathrm{~mm} \mathrm{Hg}(3.73 \mathrm{kPa})$.

We made direct field measurements of $\mathrm{PaO}_{2}$ and arterial oxygen content $\left(\mathrm{CaO}_{2}\right)$ in climbers breathing ambient air at these extreme altitudes.

\section{METHODS}

\section{STUDY PARTICIPANTS}

We obtained approval for this study from the University College London Committee on the Eth- ics of Non-NHS Human Research. All participants gave written informed consent. The subjects in this study were 10 healthy climbers $(9$ men and 1 woman, ranging in age from 22 to 48 years), who were ascending Everest by its southeast ridge as part of a medical research expedition (Caudwell Xtreme Everest). ${ }^{8,9}$

All subjects had ascended higher than $6800 \mathrm{~m}$ $(22,310 \mathrm{ft})$ without incident on previous expeditions, and all were well acclimatized, with no evidence of ill effects from high altitude or of other illnesses. Subjects who were ascending higher than $7950 \mathrm{~m}(26,083 \mathrm{ft})$ had all previously ascended higher than that altitude without incident.

\section{COLLECTION OF BLOOD SAMPLES}

Arterial blood samples were obtained in London,

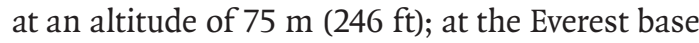
camp, at an altitude of $5300 \mathrm{~m}(17,388 \mathrm{ft})$; in Camp 2, at an altitude of $6400 \mathrm{~m}$ (20,997 ft); in Camp 3, at an altitude of $7100 \mathrm{~m}(23,294 \mathrm{ft})$; and during the descent from the summit at a feature known as the Balcony, at an altitude of $8400 \mathrm{~m}$ (27,559 ft) (Fig. 1). The samples that were obtained in London and at the Everest base camp were obtained with the subject at rest, with the use of indwelling radial arterial cannulae that were placed as part of other study protocols; these samples were analyzed immediately. Samples obtained at an altitude higher than the Everest base camp were obtained from the right femoral artery, identified by digital palpation. Intraarterial placement of the needle (21-gauge) was confirmed by pulsatile filling of a heparinized 2-ml oiled glass syringe (Fisher Scientific). Syringes were immediately sealed with an airtight cap and placed in a plastic bag, which in turn was placed in an icewater slurry inside an insulated vacuum flask. The flask was rapidly transported to a laboratory at Camp 2 in the Western Cwm; the length of time for this transfer to be completed was recorded. Barometric pressure was measured at the altitude at which the blood samples were taken, with the use of a handheld digital barometer (GPB 2300, Greisinger Electronic). Arterial samples were obtained by two investigators, both of whom had extensive experience with cannulation of the femoral artery and blood sampling.

\section{SUPPLEMENTAL OXYGEN}

Supplemental oxygen was used only at or above Camp $3(7100 \mathrm{~m})$, with the following flow rates: 2 to 3 liters per minute while the subject was 


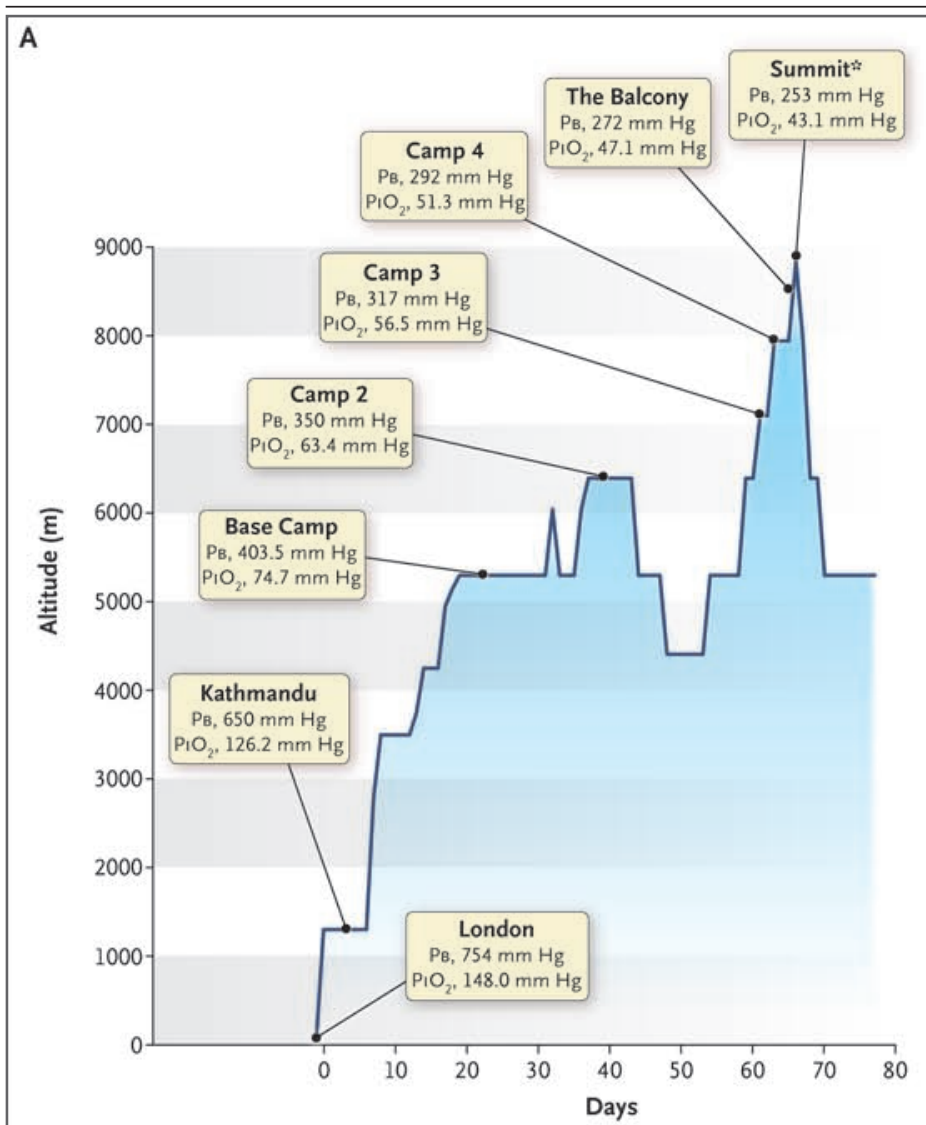

B

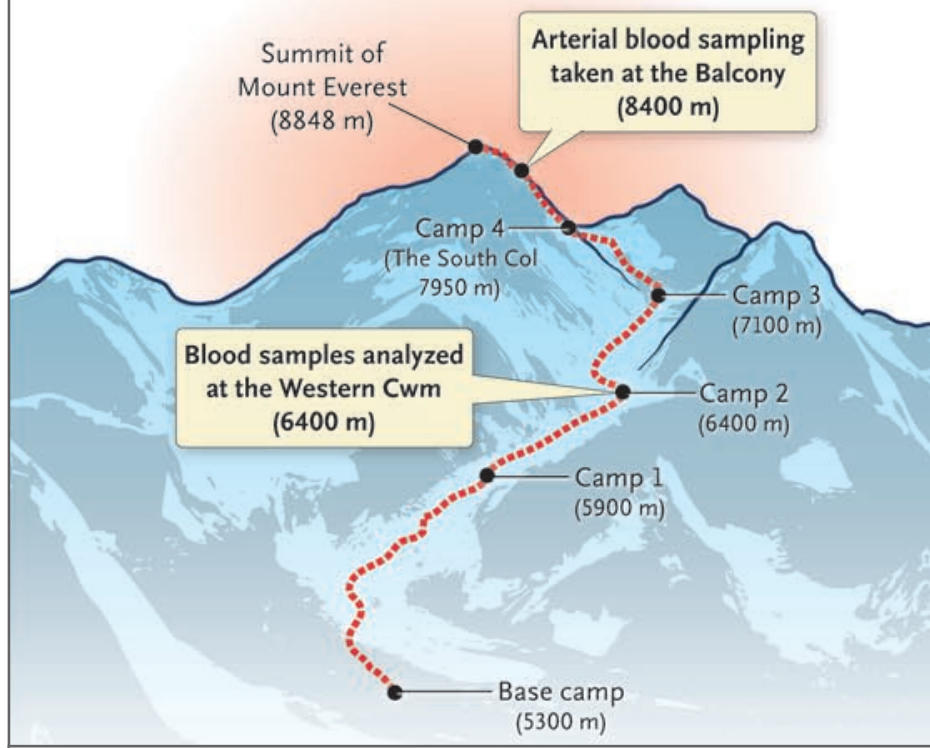

Figure 1. Barometric Pressure ( $\left.\mathrm{PB}_{\mathrm{B}}\right)$ and Partial Pressure of Inspired Oxygen $\left(\mathrm{PIO}_{2}\right)$ in Blood Samples Obtained from Subjects Breathing Ambient Air at Various Altitudes between London and the Summit of Mount Everest.

In Panel A, the measurements at the summit are reported from West et al. ${ }^{7}$ The other measurements were performed by the investigators. climbing and 0.5 liter per minute while the subject was sleeping. Supplemental oxygen was infrequently used while the subjects were resting at Camp 3 and Camp 4 (7950 m). At Camp 3, arterial samples were obtained after the subjects had been breathing ambient air for at least 4 hours. At the Balcony, samples were obtained after the subjects had been breathing ambient air for 20 minutes in order to achieve an adequate washout of supplemental oxygen.

\section{ANALYSIS OF BLOOD SAM PLES}

Arterial blood samples were analyzed with the use of the RapidLab 348 (Siemens Medical Solutions Diagnostics) blood gas analyzer, which does not contain a co-oximeter. The $\mathrm{PaO}_{2}$, the $\mathrm{PaCO}_{2}$, and the $\mathrm{pH}$ were measured. Values for the bicarbonate concentration, blood base excess, and oxygen saturation $\left(\mathrm{SaO}_{2}\right)$ were calculated with the use of formulas currently approved by the Clinical Laboratory Standards Institute ${ }^{10}$ (Table 1). The blood lactate concentration was measured with a separate device (Lactate Scout, EKF Diagnostic). Barometric pressure was measured at the site of analysis with the use of the same model of barometer as that used at the sampling site.

The blood gas analyzer was altered from its original specification so that it would function at high altitude. The analyzer's internal barometer was bypassed with a fixed resistor so that the analyzer always read as if the barometric pressure was a constant $450 \mathrm{~mm} \mathrm{Hg}(60.0 \mathrm{kPa})$, regardless of altitude. This modification was necessary in order to circumvent an inbuilt mechanism that prevented the analysis of samples at a barometric pressure lower than $400 \mathrm{~mm} \mathrm{Hg}(53.3 \mathrm{kPa})$. To replicate the barometric-pressure correction that the machine would normally apply in its unmodified form, true gas partial-pressure values were obtained by inserting the machine-derived values into Equation 1, shown in Table 1. This calculation is identical to that performed internally by the arterial blood gas analyzer during normal function at lower altitudes.

The subjects' temperatures at the time of sampling were assumed to be the same as the temperature of the blood gas analyzer - namely, $37.0^{\circ} \mathrm{C}\left(98.6^{\circ} \mathrm{F}\right)$. The analyzer was validated in a hypobaric chamber at the equivalent of $4000 \mathrm{~m}$ $(13,123 \mathrm{ft})$ and then revalidated in the field, at $5300 \mathrm{~m}$ and $6400 \mathrm{~m}$, the altitudes at which measurements of arterial blood gas were performed 
Table 1. Equations Used for the Calculation of Arterial Blood Gas Values and Arterial Oxygen Content.*

1. Actual partial pressure of oxygen in arterial blood samples $\left(\mathrm{PaO}_{2}\right)$

$\mathrm{PaO}_{2}=\frac{\text { measured } \mathrm{PB} \text { at site of } A B G \text { machine }-S V P}{\text { resistor set } \mathrm{PB} \text { (i.e., } 450 \mathrm{~mm} \mathrm{Hg})-\mathrm{SVP}} \times$ value of $\mathrm{PO}_{2}$ given by $A B G$ machine

2. Arterial oxygen saturation $\left(\mathrm{SaO}_{2}\right) \dagger$

$\mathrm{SaO}_{2}(\%)=\frac{\mathrm{N}^{4}-\left(15 \times \mathrm{N}^{3}\right)+\left(2045 \times \mathrm{N}^{2}\right)+(2000 \times \mathrm{N})}{\mathrm{N}^{4}-\left(15 \times \mathrm{N}^{3}\right)+\left(2400 \times \mathrm{N}^{2}\right)-(31,100 \times N)+\left(2.4 \times 10^{6}\right)} \times 100$

$\mathrm{N}=\mathrm{PO}_{2} \times 10^{[0.48 \times(\mathrm{PH}-7.4)-0.0013 \times \mathrm{BE}]}$

3. Bicarbonate concentration $\left(\mathrm{HCO}_{3}{ }^{-}\right) \dagger$

$\mathrm{HCO}_{3}{ }^{-}(\mathrm{mmol} /$ liter $)=0.0307 \times \mathrm{PaCO}_{2} \times 10^{(\mathrm{PH}-6.105)}$

4. Blood base excess $(\mathrm{BE}) \dagger^{\dagger}$

$\mathrm{BE}=(1-0.014 \times \mathrm{Hb}) \times\left(\mathrm{HCO}_{3}{ }^{-}-24.8\right)+(7.7+1.43 \times \mathrm{Hb}) \times(\mathrm{pH}-7.4)$

5. Partial pressure of inspired oxygen $\left(\mathrm{PIO}_{2}\right)$

$\mathrm{PlO}_{2}=(\mathrm{PB}-\mathrm{SVP}) \times \mathrm{F}_{1} \mathrm{O}_{2}$

6. Partial pressure of alveolar oxygen $\left(\mathrm{PAO}_{2}\right)$ - The "alveolar gas equation"

$\mathrm{PAO}_{2}=\mathrm{P}_{1} \mathrm{O}_{2}-\frac{\mathrm{PACO}_{2}}{\mathrm{RER}}+\left[\mathrm{PACO}_{2} \times \mathrm{FlO}_{2} \times \frac{1-\mathrm{RER}}{\mathrm{RER}}\right]$

$\mathrm{PACO}_{2}$ was assumed to be equal to $\mathrm{PaCO}_{2}$

7. Arterial oxygen content $\left(\mathrm{CaO}_{2}\right)$

$\mathrm{CaO}_{2}=\mathrm{SaO}_{2} \times \mathrm{Hb} \times 1.39+\left(\mathrm{PaO}_{2} \times 0.03\right)$

* ABG denotes arterial blood gas, $\mathrm{BE}$ base excess, $\mathrm{FIO}_{2}$ fraction of inspired oxygen, $\mathrm{Hb}$ hemoglobin concentration, $\mathrm{PACO}_{2}$ partial pressure of alveolar carbon dioxide, $\mathrm{PaCO}_{2}$ partial pressure of arterial carbon dioxide, $\mathrm{PB}$ barometric pressure, $\mathrm{PO}_{2}$ partial pressure of oxygen, RER respiratory exchange ratio, and SVP saturated vapor pressure at body temperature $(47 \mathrm{~mm} \mathrm{Hg})$.

$\dagger$ This equation is currently approved by the Clinical Laboratory Standards Institute (http://www.clsi.org). ${ }^{10}$

in this study. Validation involved the analysis of aqueous trilevel quality-control solutions (RapidQC Plus, Bayer HealthCare) with known values of $\mathrm{pH}$, $\mathrm{PaO}_{2}$, and $\mathrm{PaCO}_{2}$. Two-point calibration of the RapidLab 348 gas sensors and electrodes was performed automatically according to the manufacturer's specifications with the use of standard gases and electrolyte solutions, respectively. Each arterial blood sample was analyzed three times, and the mean of these values is reported. Because the pulse oximeters available to us were not calibrated below $70 \% \mathrm{SaO}_{2}$, we chose to calculate $\mathrm{SaO}_{2}$ using Equation 2, shown in Table 1. All reported values for $\mathrm{SaO}_{2}$ are calculated values, except for the values for four subjects at an altitude of $5300 \mathrm{~m}$; for these subjects, values obtained by peripheral-pulse oximetry (Onyx 9500, Nonin) are reported owing to an isolated failure of the $\mathrm{pH}$ electrode on the blood gas machine, an electrode that was subsequently replaced. All measured and calculated values for $\mathrm{SaO}_{2}$ at an altitude of $5300 \mathrm{~m}$ fell within the calibrated range of the pulse oximeter.

The hemoglobin concentration was measured in venous blood collected from subjects in London before the expedition, at the Everest base camp (at 2-week intervals during the expedition), and at Camp 2, with the use of a handheld photo- 


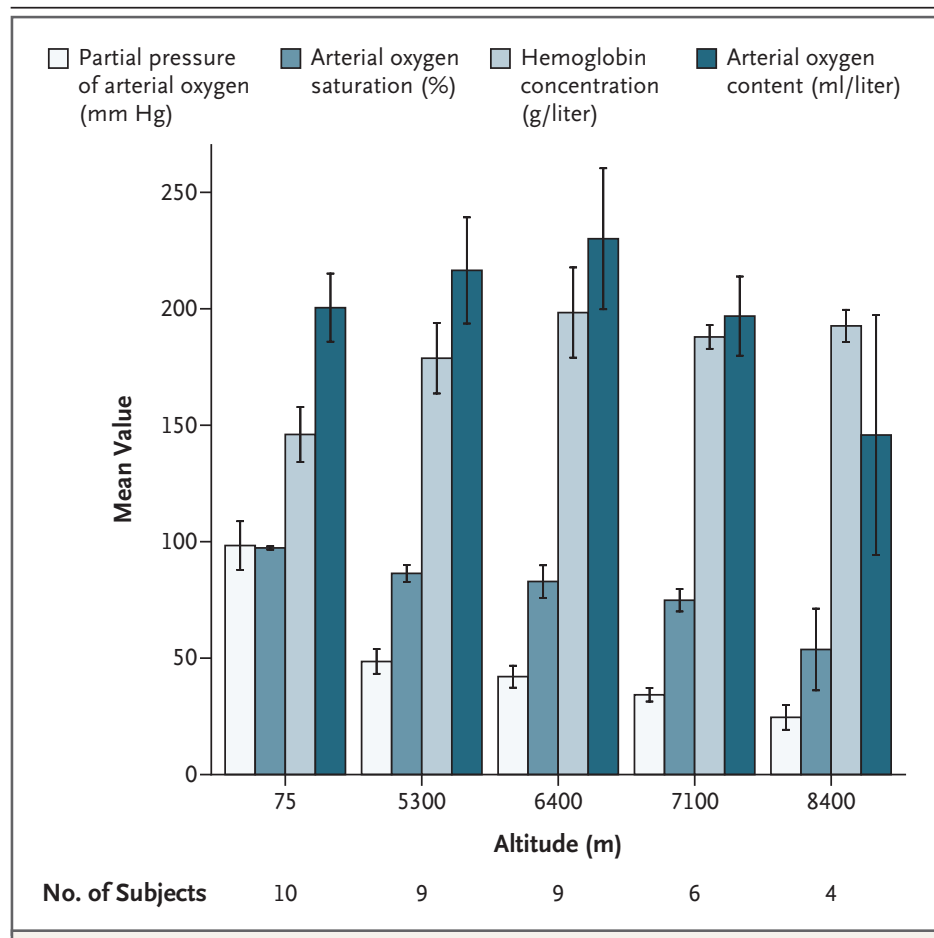

Figure 2. Changes in the Arterial Mean Partial Pressure of Oxygen, Oxygen Saturation, Hemoglobin Concentration, and Oxygen Content in Climbers on Mount Everest.

I bars denote standard deviations.

\section{RESULTS}

\section{COLLECTION OF SAMPLES}

The climbers reached the summit of Mount Everest on the morning of May 23, 2007, after having spent 60 days at an elevation higher than $2500 \mathrm{~m}$ $(8202 \mathrm{ft})$. The location, altitude, barometric pressure, and $\mathrm{PIO}_{2}$ for each sampling site are shown in Figure 1. All femoral arterial blood samples were obtained without complications on the first attempt. Ten samples were obtained in London, nine at the Everest base camp, nine at Camp 2, six at Camp 3, and four at $8400 \mathrm{~m}$. The reasons for not obtaining samples were as follows: at the Everest base camp, one subject was unwell; at Camp 2, one subject was unwell; at Camp 3, four subjects were not present when the Sherpa was available to transport the sample; and at the Balcony, two subjects did not reach this altitude, and four subjects were not present when the Sherpa was available to transport the sample. One sample at Camp 2 repeatedly clotted in the arterial blood gas machine, so no data are available for that sample. In all cases, the interval between sampling and analysis was less than 2 hours.

\section{ARTERIAL BLOOD GASES}

Measured $\mathrm{PaO}_{2}$ and hemoglobin values, along with calculated $\mathrm{SaO}_{2}$ and $\mathrm{CaO}_{2}$ values, are shown in Figure 2. The $\mathrm{CaO}_{2}$ value at sea level was maintained up to an altitude of $7100 \mathrm{~m}$ and fell below baseline only at $8400 \mathrm{~m}$; at this altitude, the mean $\mathrm{CaO}_{2}$ for the four subjects was calculated to be $145.8 \mathrm{ml}$ per liter. Mean $\mathrm{PaCO}_{2}$ values fell with increasing altitude, from $36.6 \mathrm{~mm} \mathrm{Hg}(4.88 \mathrm{kPa})$ at sea level to $20.4 \mathrm{~mm} \mathrm{Hg}(2.72 \mathrm{kPa})$ at $5300 \mathrm{~m}$, $18.2 \mathrm{~mm} \mathrm{Hg}(2.43 \mathrm{kPa})$ at $6400 \mathrm{~m}$, and $16.7 \mathrm{~mm} \mathrm{Hg}$ (2.23 kPa) at $7100 \mathrm{~m}$; corresponding $\mathrm{pH}$ values were 7.40, 7.46, 7.51, and 7.53.

The results of the arterial blood gas analysis and the hemoglobin and lactate concentrations in four subjects at $8400 \mathrm{~m}$ are shown in Table 2. The mean $\mathrm{PaO}_{2}$ and $\mathrm{PaCO}_{2}$ values were $24.6 \mathrm{~mm} \mathrm{Hg}$ (3.28 kPa) and $13.3 \mathrm{~mm} \mathrm{Hg}(1.77 \mathrm{kPa})$, respectively. The mean $\mathrm{PIO}_{2}$ value at $8400 \mathrm{~m}$ was calculated to be $47.0 \mathrm{~mm} \mathrm{Hg}(6.27 \mathrm{kPa})$ at the time of arterial sampling. Calculated values for $\mathrm{PAO}_{2}$, resting respiratory exchange ratios, and the alveolar-arterial oxygen difference in four subjects at $8400 \mathrm{~m}$ are shown in Table 2. The mean $\mathrm{PAO}_{2}$ and 


\begin{tabular}{|c|c|c|c|c|c|}
\hline \multirow[t]{2}{*}{ Variable } & \multicolumn{4}{|c|}{ Subject No. } & \multirow[t]{2}{*}{ Group Mean } \\
\hline & 1 & 2 & 3 & 4 & \\
\hline $\mathrm{pH}$ & 7.55 & 7.45 & 7.52 & 7.60 & 7.53 \\
\hline $\mathrm{PaO}_{2}(\mathrm{~mm} \mathrm{Hg}) \dagger$ & 29.5 & 19.1 & 21.0 & 28.7 & 24.6 \\
\hline $\mathrm{PaCO}_{2}(\mathrm{~mm} \mathrm{Hg}) \dagger$ & 12.3 & 15.7 & 15.0 & 10.3 & 13.3 \\
\hline Bicarbonate (mmol/liter) $\ddagger$ & 10.5 & 10.67 & 11.97 & 9.87 & 10.8 \\
\hline Base excess of blood $t$ & -6.3 & -9.16 & -6.39 & -5.71 & -6.9 \\
\hline Lactate concentration (mmol/liter) & 2.0 & 2.0 & 2.9 & 1.8 & 2.2 \\
\hline $\mathrm{SaO}_{2}(\%) \div$ & 68.1 & 34.4 & 43.7 & 69.7 & 54.0 \\
\hline Hemoglobin $(\mathrm{g} / \mathrm{dl}) \int$ & 20.2 & 18.7 & 18.8 & 19.4 & 19.3 \\
\hline Respiratory exchange ratio & 0.81 & $0.74 \|$ & 0.72 & 0.70 & 0.74 \\
\hline $\mathrm{PAO}_{2}-\mathrm{mm} \mathrm{Hg} \dagger^{\prime} * *$ & 32.4 & 26.9 & 27.4 & 33.2 & 30.0 \\
\hline Alveolar-arterial oxygen difference $-\mathrm{mm} \mathrm{Hg \dagger}$ & 2.89 & 7.81 & 6.44 & 4.51 & 5.41 \\
\hline \multicolumn{6}{|c|}{$\begin{array}{l}\mathrm{PaCO} \text { denotes partial pressure of arterial carbon dioxide, } \mathrm{PAO}_{2} \text { partial pressure of alveolar oxygen, } \mathrm{PaO}_{2} \text { partial pres- } \\
\text { sure of arterial oxygen, and } \mathrm{SaO}_{2} \text { calculated arterial oxygen saturation. } \\
\text { To convert the values for } \mathrm{PaO}_{2}, \mathrm{PaCO}_{2}, \mathrm{PAO}_{2} \text {, and the alveolar-arterial oxygen difference to kilopascals, multiply by } \\
0.1333 \text {. } \\
\text { These values were calculated with the use of the algorithms currently approved by the Clinical Laboratory Standards } \\
\text { Institute. } \\
\text { The values for hemoglobin are the mean values of measurements obtained at } 5300 \mathrm{~m}(17,388 \mathrm{ft}) 9 \text { days before and } 8 \\
\text { days after the arterial blood sampling. } \\
\text { The respiratory exchange ratio was measured at an elevation of } 7950 \mathrm{~m} \text { while the subject was resting. } \\
\text { No measured respiratory exchange ratio was available for this subject; the value was derived from the mean values } \\
\text { for the other three subjects. } \\
\mathrm{PAO}_{2} \text { was calculated with the use of the full alveolar gas equation. }\end{array}$} \\
\hline
\end{tabular}

the mean alveolar-arterial oxygen difference were $30.0 \mathrm{~mm} \mathrm{Hg}(4.00 \mathrm{kPa})$ and $5.4 \mathrm{~mm} \mathrm{Hg}(0.72 \mathrm{kPa})$, respectively. None of the subjects were considered, on clinical grounds, to have high-altitude pulmonary edema during the study period.

\section{DISCUSSION}

These measurements of arterial blood gases and hemoglobin levels in climbers on Mount Everest provide a picture of the pattern and limits of changes in human blood gases in response to hypobaric hypoxia on the earth's highest mountain. Because of adverse weather conditions, we were unable to obtain arterial samples at the summit of Mount Everest as originally planned. Consequently, the samples at the highest altitude were obtained during the descent from the summit. A small shelter was erected at the first safe location, an area known as the Balcony, which is located at an altitude of $8400 \mathrm{~m}$, and the blood sampling took place in this shelter. The values for $\mathrm{PaO}_{2}$ and $\mathrm{SaO}_{2}$ reported here are, to our knowledge, among the lowest ever documented in humans. The results of a study of alveolar breath samples obtained from divers suggest that breathhold divers may have $\mathrm{PaO}_{2}$ levels that are lower than $30 \mathrm{~mm} \mathrm{Hg}$ (4.0 kPa), but no direct measurements have been reported. ${ }^{11}$ Similar values have been reported in a study of samples obtained at a high altitude, but in that study, measurements were obtained from subjects who had high-altitude pulmonary edema. ${ }^{12,13}$

Decreases in $\mathrm{PaO}_{2}$ are broadly proportional to the fall in barometric pressure with increasing altitude, whereas $\mathrm{SaO}_{2}$ is relatively well maintained (in relation to barometric-pressure changes) owing to the characteristics of the oxygen-hemoglobin dissociation curve and the effects of respiratory acclimatization (decreased $\mathrm{PaCO}_{2}$ ). Increases in the hemoglobin concentration compensate for the fall in $\mathrm{SaO}_{2}$ such that $\mathrm{CaO}_{2}$ is maintained until 
a person reaches an altitude of at least $7100 \mathrm{~m}$. Thus, changes in $\mathrm{CaO}_{2}$ do not provide an explanation for the significant limitations in individual performance previously reported at these altitudes (a reduction in maximum oxygen consumption of 30 to $35 \%$ at $\left.5300 \mathrm{~m}^{1,7}\right) . \mathrm{CaO}_{2}$ at $8400 \mathrm{~m}$ is significantly lower than that at sea level, and the marked interindividual variability at this altitude is related predominantly to differences in $\mathrm{SaO}_{2}$, probably reflecting a combination of variation in ventilatory acclimatization, hypoxic ventilatory response, hypoxic ventilatory depression, and the alveolar-arterial oxygen difference, as discussed below.

At the highest altitude at which samples were obtained, the subjects had an impressive adaptive response (i.e., acclimatization) to prolonged and extreme environmental hypoxia. Persons who are not acclimatized lose consciousness within 2 to 3 minutes when they are exposed suddenly to levels of ambient hypoxia equivalent to those at altitudes higher than $8534 \mathrm{~m}(27,999 \mathrm{ft}) .{ }^{14}$ In contrast, our subjects had apparently clear cognition, as evidenced by effective radio communication and, in the case of two of the subjects, the performance of complication-free sampling of arterial blood gases. The absence of obvious neurocognitive abnormalities suggests that cerebral hypoxia was not manifested as a substantial dysfunction at the time of blood sampling. This is of interest in view of the evidence that there is a risk of long-term cognitive deficit and structural neurologic damage from exposure to these extreme altitudes. ${ }^{15-17}$ Despite chronic hypoxemia, none of the subjects in this study had clinically significant hyperlactatemia (mean lactate concentration, $2.2 \mathrm{mmol}$ per liter at the highest altitude), consistent with findings in resting subjects exposed to hypobaric hypoxia. ${ }^{5}$ This suggests that anaerobic metabolism does not contribute substantially to energy production at an extreme altitude while a person is at rest. An alternative, or additional, explanation is the possibility of increased lactate use as a fuel source at extreme altitudes. ${ }^{18}$

We cannot exclude the possibility that the use of supplemental oxygen at and above Camp 3 was a confounding influence on the acclimatization process and thus on $\mathrm{PaO}_{2}$ and $\mathrm{PaCO}_{2}$. Supplemental oxygen benefits climbers subjectively and improves $\mathrm{SaO}_{2}$ in the resting state and during exercise. ${ }^{19}$ During this study, the safety benefits related to supplemental oxygen were considered to be of overriding importance while the subjects were climbing on Mount Everest. ${ }^{20}$ We believe that the 20-minute rest period that the subjects had without supplemental oxygen before arterial sampling should have been more than adequate to ensure a washout of supplemental oxygen from the circulation. However, the effects on ventilation of suddenly removing supplemental oxygen at such an altitude are unknown. Climbers who reach the summit of Mount Everest without using supplemental oxygen may have more effective ventilatory acclimatization than those who use supplemental oxygen, and they may therefore have a higher $\mathrm{PaO}_{2}$ while breathing ambient air than do those who choose to use supplemental oxygen. Removing supplemental oxygen in a hypoxic environment is known to trigger two sequential yet variable phenomena. The hypoxic ventilatory response leads to hyperventilation within minutes after exposure to hypoxia and is followed by hypoxic ventilatory depression approximately 10 to 30 minutes after exposure. ${ }^{21}$ The effect of these opposing responses to hypoxia on the $\mathrm{PaO}_{2}$ and $\mathrm{PaCO}_{2}$ values in this study is difficult to quantify. Interindividual variability in the hypoxic ventilatory response and hypoxic ventilatory depression may account for the variability in arterial blood gas values in our subjects as compared with the results of a study involving subjects in a hypobaric chamber, in which supplemental oxygen was not used immediately before sampling. ${ }^{5}$

The methods of storage and transportation of the blood samples in this study were used by our group on two previous expeditions to extreme altitudes and were shown to be effective. The time lapse between sampling and analysis was 2 hours or less in all cases. The effect of storing blood in this manner has been described previously ${ }^{22}$; the partial pressure of oxygen in the blood samples rose approximately $0.75 \mathrm{~mm} \mathrm{Hg}(0.1 \mathrm{kPa})$ after 2 hours of storage. Our own experiments at sea level have shown a similar mean rise in the partial pressure of oxygen $(1.1 \mathrm{~mm} \mathrm{Hg}$ [0.15 kPa]) in samples of venous blood after 2 hours. Therefore, any effect of the duration of storage and transportation on the reported values would tend to lead to a small overestimation of measured $\mathrm{PaO}_{2}$.

Our findings are consistent with the results of the previous three studies of $\mathrm{PaO}_{2}$ in extreme 
hypobaric conditions..$^{5-7}$ The mean measured $\mathrm{PaO}_{2}$ in our study was $24.6 \mathrm{~mm} \mathrm{Hg}(3.28 \mathrm{kPa})$ at $8400 \mathrm{~m}$, as compared with $30.3 \mathrm{~mm} \mathrm{Hg}(4.04 \mathrm{kPa})^{5}$ or $30.6 \mathrm{~mm} \mathrm{Hg}(4.08 \mathrm{KPa})^{6}$ at a simulated altitude of $8848 \mathrm{~m}$, and $28.0 \mathrm{~mm} \mathrm{Hg}(3.73 \mathrm{kPa})$ as estimated by West et al. from an alveolar gas sample obtained at $8848 \mathrm{~m} .^{7}$ The mean $\mathrm{PaO}_{2}$ in our subjects was lower than these values, despite the fact that our subjects were at a slightly higher barometric pressure (lower altitude). The $\mathrm{PaCO}_{2}$ reported in the study by West et al. ${ }^{7}$ was only $7.5 \mathrm{~mm} \mathrm{Hg}(1.0 \mathrm{kPa})$, slightly more than half the mean $\mathrm{PaCO}_{2}$ reported in this study $(13.3 \mathrm{~mm} \mathrm{Hg}$ [1.78 kPa]). This finding may be explained by the fact that the subject from whom the alveolar gas sample was collected in the study of West et al. ${ }^{7}$ was known to have an extremely brisk hypoxic ventilatory response. ${ }^{23}$ Possible explanations for the differences between the data in this study and the results of previous hypobaric-chamber studies may be related to differences in ascent profiles, activity levels, and the use of supplemental oxygen. In the hypobaric-chamber studies, the subjects were exposed to hypobaric conditions for a period of 37 to 40 days, ${ }^{5,6}$ as compared with 60 days in this study (Fig. 1), and although they underwent periodic exercise tests, activity levels were much lower than those in our subjects, who were climbing to the summit of Everest. Whereas subjects in our study used supplemental oxygen as described, subjects in Operation Everest II were similarly exposed to an elevated fraction of inspired oxygen either because the chamber pressure was increased at night to help them sleep or during the conduct of pulmonary artery catheterization studies. ${ }^{5,24}$

At an altitude of $8400 \mathrm{~m}$, the mean calculated $\mathrm{P}_{\mathrm{AO}}$, was $30.0 \mathrm{~mm} \mathrm{Hg}(4.00 \mathrm{kPa})$, and the mean calculated alveolar-arterial oxygen difference was $5.4 \mathrm{~mm} \mathrm{Hg}(0.72 \mathrm{kPa})$ (Table 2). It is known that the alveolar-arterial oxygen difference decreases as the $\mathrm{PIO}_{2}$ falls. ${ }^{25}$ Both theoretical considerations and empirical data suggest that the alveolararterial oxygen difference should be less than $2 \mathrm{~mm} \mathrm{Hg}(0.27 \mathrm{kPa})$ under these conditions ${ }^{26}$; Sutton et al. report a mean alveolar-arterial oxygen difference of $1.5 \mathrm{~mm} \mathrm{Hg}(0.20 \mathrm{kPa})$ in resting healthy persons at the simulated altitude of $8848 \mathrm{~m} .^{5}$

Hypoxia associated with an increased alveolararterial oxygen difference may be attributable to shunting, a ventilation-perfusion mismatch, or a limitation in pulmonary diffusion. We speculate that the relatively high alveolar-arterial oxygen difference in the subjects in this study may be the result of subclinical high-altitude pulmonary edema contributing to both a ventilation-perfusion mismatch and impairment of pulmonary diffusion. An alternative explanation might be disequilibrium in pulmonary alveolar-end-capillary diffusion, which has been shown to occur in conditions of hypobaric hypoxia. ${ }^{27,28}$ Previous investigators have observed an increased alveolararterial oxygen gradient after strenuous exercise in subjects exposed to hypobaric hypoxia, ${ }^{25,29,30}$ and this may be a key difference between the results of this study and those of previous investigations involving subjects in a hypobaric chamber.

In our study, arterial blood sampling was performed with subjects in the supine position, and this factor may have confounded measurements through mechanisms such as increased basal atelectasis or central fluid shifts that can be detrimental to pulmonary gas exchange. $\mathrm{PaO}_{2}$ has been reported to be inversely related to the alveolararterial oxygen difference ${ }^{30}$; this finding may explain the low $\mathrm{PaO}_{2}$ in Subject $2(19.1 \mathrm{~mm} \mathrm{Hg}$ [2.55 kPa]), the subject in the group who had the highest alveolar-arterial oxygen difference. The respiratory exchange ratios in subjects who had just reached the summit of Mount Everest may be higher than those that were measured at a resting steady state the previous day on the South $\mathrm{Col}$ at $7950 \mathrm{~m}$. However, such an elevation in respiratory exchange ratios would only serve to increase the alveolar-arterial oxygen difference and increase the significance of these findings. For example, if the respiratory exchange ratio was assumed to be 1.0 in all four subjects at the time of blood sampling, the mean alveolar-arterial oxygen difference would be $9.1 \mathrm{~mm} \mathrm{Hg}(1.21 \mathrm{kPa})$, instead of $5.4 \mathrm{~mm} \mathrm{Hg}(0.72 \mathrm{kPa})$.

Tissue hypoxia is a universal phenomenon among persons who are critically ill ${ }^{31}$ and is often the result of arterial hypoxemia. In conjunction with the initiating factor and the presence of any coexisting condition, hypoxia triggers numerous adaptive and maladaptive systemic responses that remain poorly understood. Defining the limits of hypoxia tolerance is of direct relevance to physicians who care for critically ill patients because many interventions that are aimed at restoring or maintaining cellular oxygenation have proven ineffective or even detrimental. For ex- 
ample, a high $\mathrm{PIO}_{2}$ can have pulmonary toxic effects. ${ }^{32}$ Moreover among patients with established critical illness, increasing the hemoglobin concentration to increase oxygen carriage may not provide a clinical benefit, ${ }^{33}$ and a goal-directed elevation of systemic oxygen can be detrimental. ${ }^{34}$ Useful insights may be gained by examining the biophysiologic responses of healthy persons who are exposed to low levels of environmental oxygen.

In summary, we report field measurements of the partial pressure of oxygen and carbon dioxide, $\mathrm{pH}$, and hemoglobin and lactate concentrations in the arterial blood of humans at extreme altitudes. We speculate that the calculated alveolar-arterial oxygen difference in these subjects suggests a degree of functional limitation in pulmonary diffusion or subclinical pulmonary edema, conditions that may explain why the values for $\mathrm{PaO}_{2}$ are lower than expected.

Supported by Mr. John Caudwell, BOC Medical (now part of Linde Gas Therapeutics), Eli Lilly, the London Clinic, Smiths
Medical, Deltex Medical, and the Rolex Foundation (unrestricted grants), the Association of Anaesthetists of Great Britain and Ireland, the United Kingdom Intensive Care Foundation, and the Sir Halley Stewart Trust. Dr. Martin is a Critical Care Scholar of the London Clinic, and Dr. Levett is a Fellow of the Association of Anaesthetists of Great Britain and Ireland. Some of this work was undertaken at University College London Hospital-University College London Comprehensive Biomedical Research Centre, which received a proportion of funding from the United Kingdom Department of Health's National Institute for Health Research Biomedical Research Centres funding scheme. Caudwell Xtreme Everest is a research project coordinated by the Centre for Altitude, Space, and Extreme Environment Medicine, University College London. Membership, roles, and responsibilities of the Caudwell Xtreme Everest Research Group can be found at www.caudwell-xtreme-everest.co.uk/team.

Dr. Grocott reports receiving lecture fees from Eli Lilly and BOC Medical and grant support from BOC Medical, Eli Lilly, and Smiths Medical; Dr. Martin, lecture fees from Siemens; and Dr. McMorrow, grant support from Smiths Medical. No other potential conflict of interest relevant to this article was reported.

We thank the staff of Siemens, in particular Robert Mayall and Steve Carey, for their continual support to us in carrying out these measurements; Pasang Tenzing Sherpa for carrying the samples from the Balcony to Camp 2 in less than 2 hours; the Caudwell Xtreme Everest volunteers who trekked to the Everest base camp; and Tom Hornbein, Erik Swenson, Monty Mythen, and Mervyn Singer for their advice during the preparation of the manuscript.

\section{APPENDIX}

The members of the Caudwell Xtreme Everest Research Group are as follows: Investigators - V. Ahuja, G. Aref-Adib, R. Burnham, A. Chisholm, K. Clarke, D. Coates, M. Coates, D. Cook, M. Cox, S. Dhillon, C. Dougall, P. Doyle, P. Duncan, M. Edsell, L. Edwards, L. Evans, P. Gardiner, M. Grocott, P. Gunning, N. Hart, J. Harrington, J. Harvey, C. Holloway, D. Howard, D. Hurlbut, C. Imray, C. Ince, M. Jonas, J. van der Kaaij, M. Khosravi, N. Kolfschoten, D. Levett, H. Luery, A. Luks, D. Martin, R. McMorrow, P. Meale, K. Mitchell, H. Montgomery, G. Morgan, J. Morgan, A. Murray, M. Mythen, S. Newman, M. O’Dwyer, J. Pate, T. Plant, M. Pun, P. Richards, A. Richardson, G. Rodway, J. Simpson, C. Stroud, M. Stroud, J. Stygal, B. Symons, P. Szawarski, A. Van Tulleken, C. Van Tulleken, A. Vercueil, L. Wandrag, M. Wilson, J. Windsor; Scientific Advisory Group - B. Basnyat, C. Clarke, T. Hornbein, J. Milledge, J. West.

REFERENCES

1. Cerretelli P. Limiting factors to oxygen transport on Mount Everest. J Appl Physiol 1976;40:658-67.

2. West JB, Boyer SJ, Graber DJ, et al. Maximal exercise at extreme altitudes on Mount Everest. J Appl Physiol 1983;55:68898.

3. West JB, Lahiri S, Maret KH, Peters RM Jr, Pizzo CJ. Barometric pressures at extreme altitudes on Mt. Everest: physiological significance. J Appl Physiol 1983; 54:1188-94.

4. Messner R. Everest: expedition to the ultimate. London: Kaye \& Ward, 1979.

5. Sutton JR, Reeves JT, Wagner PD, et al. Operation Everest II: oxygen transport during exercise at extreme simulated altitude. J Appl Physiol 1988;64:1309-21.

6. Richalet JP, Robach P, Jarrot S, et al. Operation Everest III (COMEX '97): effects of prolonged and progressive hypoxia on humans during a simulated ascent to $8,848 \mathrm{M}$ in a hypobaric chamber. Adv Exp Med Biol 1999;474:297-317.

7. West JB, Hackett PH, Maret KH, et al. Pulmonary gas exchange on the summit of Mount Everest. J Appl Physiol 1983;55: 678-87.
8. Grocott M, Richardson A, Montgomery H, Mythen M. Caudwell Xtreme Everest: a field study of human adaptation to hypoxia. Crit Care 2007;11:151.

9. Proffitt F. Physiology: science in the 'death zone.' Science 2005;308:1541-2. 10. Ehrmeyer S, Burnett RW, Chatburn RL, et al. Fractional oxyhemoglobin, oxygen content and saturation, and related quantities in blood: terminology, measurement, and reporting. Vol. 12. No. 11. Wayne, PA: National Committee for Clinical Laboratory Standards, 1997. (NCCLS document C25-A.)

11. Lindholm P, Lundgren CE. Alveolar gas composition before and after maximal breath-holds in competitive divers. Undersea Hyperb Med 2006;33:463-7.

12. Bartsch P, Waber U, Haeberli A, et al Enhanced fibrin formation in high-altitude pulmonary edema. J Appl Physiol 1987;63:752-7.

13. Scherrer U, Vollenweider L, Delabays A et al. Inhaled nitric oxide for high-altitude pulmonary edema. N Engl J Med 1996; 334:624-9.

14. Ernsting J, Sharp GR, Harding RM Hypoxia and hyperventilation. In: Ernst- ing J, King PF, eds. Aviation medicine. 2nd ed. London: Butterworths, 1988:46-59. 15. Garrido E, Segura R, Capdevila A, et al. New evidence from magnetic resonance imaging of brain changes after climbs at extreme altitude. Eur J Appl Physiol Occup Physiol 1995; 70:477-81.

16. Hornbein TF, Townes BD, Schoene RB, Sutton JR, Houston CS. The cost to the central nervous system of climbing to extremely high altitude. N Engl J Med 1989; 321:1714-9.

17. Regard M, Oelz O, Brugger P, Landis T. Persistent cognitive impairment in climbers after repeated exposure to extreme altitude. Neurology 1989;39:210-3. 18. Cerretelli P, Samaja M. Acid-base balance at exercise in normoxia and in chronic hypoxia: revisiting the "lactate paradox." Eur J Appl Physiol 2003;90:43148.

19. Windsor JS, Rodway GW. Supplemental oxygen effects on ventilation in acclimatized subjects exercising at $5700 \mathrm{~m}$ altitude. Aviat Space Environ Med 2007;78: 426-9.

20. Huey RB, Eguskitza X. Supplemental oxygen and mountaineer death rates on 
Everest and K2. JAMA 2000;284:181. [Erratum, JAMA 2000;284:2999.]

21. Smith CA, Dempsey JA, Hornbein TF. Control of breathing at high altitude. In: Hornbein TF, Schoene RB, eds. High altitude: an exploration of human adaptation. New York: Marcel Dekker, 2001:139-73.

22. Catron TF, Powell FL, West JB. A strategy for determining arterial blood gases on the summit of Mt. Everest. BMC Physiol 2006;6:3.

23. Schoene RB, Lahiri S, Hackett PH, et al. Relationship of hypoxic ventilatory response to exercise performance on Mount Everest. J Appl Physiol 1984;56:1478-83.

24. Houston CS, Sutton JR, Cymerman A, Reeves JT. Operation Everest II: man at extreme altitude. J Appl Physiol 1987;63:87782.

25. Wagner PD, Sutton JR, Reeves JT, Cymerman A, Groves BM, Malconian MK. Operation Everest II: pulmonary gas exchange during a simulated ascent of
Mt. Everest. J Appl Physiol 1987;63:234859.

26. Hammond MD, Gale GE, Kapitan KS, Ries A, Wagner PD. Pulmonary gas exchange in humans during normobaric hypoxic exercise. J Appl Physiol 1986;61: 1749-57.

27. Torre-Bueno JR, Wagner PD, Saltzman HA, Gale GE, Moon RE. Diffusion limitation in normal humans during exercise at sea level and simulated altitude. J Appl Physiol 1985;58:989-95.

28. Wagner PD, Gale GE, Moon RE, TorreBueno JR, Stolp BW, Saltzman HA. Pulmonary gas exchange in humans exercising at sea level and simulated altitude. J Appl Physiol 1986;61:260-70.

29. Kronenberg RS, Safar P, Lee J, et al. Pulmonary artery pressure and alveolar gas exchange in man during acclimatization to $12,470 \mathrm{ft}$. J Clin Invest $1971 ; 50$ : 827-37.

30. Reeves JT, Halpin J, Cohn JE, Daoud F.
Increased alveolar-arterial oxygen difference during simulated high-altitude exposure. J Appl Physiol 1969;27:658-61.

31. Grocott M, Montgomery H, Vercueil A. High-altitude physiology and pathophysiology: implications and relevance for intensive care medicine. Crit Care 2007;11: 203.

32. Jackson RM. Pulmonary oxygen toxicity. Chest 1985;88:900-5.

33. Hébert PC, Wells G, Blajchman MA, et al. A multicenter, randomized, controlled clinical trial of transfusion requirements in critical care: transfusion requirements in critical care investigators. $\mathrm{N}$ Engl J Med 1999;340:409-17. [Erratum, N Engl J Med 1999;340:1056.]

34. Hayes MA, Timmins AC, Yau EH, Palazzo M, Hinds CJ, Watson D. Elevation of systemic oxygen delivery in the treatment of critically ill patients. N Engl J Med 1994;330:1717-22.

Copyright (c) 2009 Massachusetts Medical Society.

FULL TEXT OF ALL JOURNAL ARTICLES ON THE WORLD WIDE WEB

Access to the complete text of the Journal on the Internet is free to all subscribers. To use this Web site, subscribers should go to the Journal's home page (NEJM.org) and register by entering their names and subscriber numbers as they appear on their mailing labels. After this one-time registration, subscribers can use their passwords to log on for electronic access to the entire Journal from any computer that is connected to the Internet. Features include a library of all issues since January 1993 and abstracts since January 1975, a full-text search capacity, and a personal archive for saving articles and search results of interest. All articles can be printed in a format that is virtually identical to that of the typeset pages. Beginning 6 months after publication, the full text of all Original Articles and Special Articles is available free to nonsubscribers. 